\title{
EMISSION OF VOLATILE CAMPHOR COMPOUNDS FROM CINNAMOMUM CAMPHORA WOOD
}

\author{
Quan Li ${ }^{1,2}$ \\ ${ }^{1}$ Fujian Agriculture and Forestry University \\ CHINA \\ 2Kaili University \\ China \\ Huimin Z Hang \\ Guizhou University \\ China \\ Hongguang Yan \\ Kaili University \\ CHINA \\ Wenyu Qi, Jinguo Lin, JiQing Li \\ Fujian Agriculture and Forestry University \\ CHINA \\ (Received October 20I9)
}

\begin{abstract}
Essential oil volatilization of Cinnamomum camphora (L.) Presl can positively affect indoor air quality through insect dispersal, antibacterial effects, and inhibiting decay, and thus is an important economic species in China. Camphor is the most abundant aromatic compound in C. camphora, although how time and temperature affect the release of the camphor is unknown. To address this question Cinnamomum camphora (C. camphora) wood was investigated using headspace gas chromatography (HS-GC). Camphor decreased with increasing detection times over temperatures of different temperature. During the detection, the release rate of camphor decreased rapidly with increased heating time in the first $2.5 \mathrm{~h}$, and leveled-off after $2.5 \mathrm{~h}$. The release of camphor at different temperatures was linear between $0 \sim 1.4 \mathrm{~h}$.

By fitting this linear model with reaction temperature camphor release could be expressed as $\mathrm{Y}=-75.369+2.3786 . \mathrm{T}+(41.125-1.1972 . \mathrm{T})$. Evaluating the release of camphor from C. camphora wood and creating a model may be useful for promoting its application in the medical and chemical industries.
\end{abstract}

KEYWORDS: Camphor, volatilization process, release rate, empirical model, headspace gas chromatography (HS-GC), Cinnamomum camphora. 


\section{INTRODUCTION}

In addition to carbon dioxide absorbance and oxygen production, plants can also release some phytoncidere that are beneficial for human health (Korukluoglu et al. 2009). Many species of softwood can emit fragrant aromas, with the efficacy of sterilization and air purification. Some essential oils extracted from wood contain distinctive aromas, which can kill bacteria and fungi. Some extracts can also positively affect the human immune system (Liu et al. 2019, Johann et al. 2010), but have a multitude of other purposes, such as food flavoring agents, preservatives, and antioxidants. There are many components in volatile matter have strong physiological activity (Kusumoto and Shibutani 2015, Ubeda et al. 2011). The influence of aromas on physiology and psychical well-being of humans has long been recognized in human physiology and psychology through aromatherapy and forest bathing (Olabode and Arueya 2016, Staszek et al. 2013). The contents and compositions of volatile has a great different in different tree species (Alves and Franco 2003, Hyun et al. 2015). For example, $\alpha$ and $\beta$-pinene extracted from wood are important raw materials for synthesis of camphor and various spices. The use of these woods or solid wood furniture in the home allows the volatile constituents to release naturally, changing the indoor air environment and affecting human physical and mental health (Buchbauer and Wallner 2016). Therefore, investigating the release of volatile compounds from wood widely used indoors for decoration and furniture has significance to human health.

C. camphora is a common tree used in landscaping in south China, because of its ability to purify toxic air and the wood is decay resistance (Roszaini et al. 2013, Li and Qi 2019). Technological developments have enabled the determination of volatile components in plants using solid phase microextraction (SPME) technology (Calejo et al. 2016, Menéndez et al. 2004, Shen et al. 2012). For many years, the public has understood that furniture made from C. camphora can lower pest prevalence (Ibrahim et al. 2008) and that the aroma can have a beneficial effect to health. However, the methodology surrounding the release of the volatile compounds is not fully understood (Miyazawa et al. 2001). To better understand this release mechanism, headspace gas chromatography (HS-GC) was employed to study these volatile substances and provide a scientific basis and theoretical reference for the development and utilization in wood protection, medicine, food and chemical industry utilizing C. camphora wood. HS-GC is a rapidly developing technology with wide application prospects to study volatile components in trace quantities. Jensen used the emission chamber testing method to examine the wood-based materials commonly used in furniture with a qualitative screening and quantitative determination of volatile organic compounds (Jensen et al. 2001). Cox et al. (2002) built a model for predicting the emission rate of volatile organic compounds from vinyl flooring, a model that has proven to be effective in small-scale chamber tests. Zhong et al. (2015) investigated the main volatile constituents of $C$. pinnatifida $(\mathrm{FCP})$ fruit during the stir-frying process showing increases in volatile release with increases in time. Hsiumei et al. (2010) researched the emission factor of carbonyl compounds in essential oil exhaust. Dubrova et al. (1990) determined the evaporation rate of essential oils, perfumery compositions, and perfumes using HS-GC with open-tubular columns. HS-GC was used previously to reveal the standard release of camphor from C. camphora wood under different conditions, but under a constant time and temperature (Shen et al. 2018). This analysis laid the foundation for the conditions of camphor release in C. camphora under different temperatures in different seasons (Wang et al. 2016). The proposed research has great realistic significance for comprehensively understanding the release mechanism of camphor from C. camphora wood. 


\section{MATERIAL AND METHODS}

\section{Materials}

C. camphora wood, that was $40 \sim 50$ years old, was collected from the streets of Fuzhou, China. The camphor xylem was cut into blocks of $4 \times 4 \times 50 \mathrm{~mm}$ (radial $\times$ tangential $\times$ longitudinal). Blocks were taken into a headspace bottle by applying HS-GC. Chemical reagents including $\alpha$-terpineol, eucalyptol (chromatographically pure), methanol (analytically pure) were purchased from Shanghai Chemical Reagent Factory (Shanghai, China).

\section{Main instruments and devices}

Auto HS automatic headspace sampler (DANI HS86.50, Italy), gas chromatography (Agilent GC7890A, USA), DB-5 chromatography column, FID detector, gland device, preassembled cap and septa for $21.6 \mathrm{ml}$ crimp neck headspace vial, microinjector $(10 \mu \mathrm{l})$, pipette $(10 \sim 100 \mu \mathrm{l}, 1000$ $\sim 5000 \mu \mathrm{l}$ ), Alumina gauze (Specification 180\#).

\section{Standards and sample preparation}

The mixed standard solution was camphor $0.1045 \mathrm{~g}, 100 \mu \mathrm{l}$ of each eucalyptol and $\alpha$-terpineol were added into $9.8 \mathrm{ml}$ methanol, shaken and preserved at low temperatures in darkness (Lisec et al. 2006). Buffing the surface of C. camphora wood block by alumina gauze was done to each of the four wide sides in rectangular buffing 5 times, the upper and lower two facet buffing 3 times. After buffing, the specimen was loaded into the headspace bottle immediately and covered. Under headspace temperatures of $40^{\circ} \mathrm{C}, 50^{\circ} \mathrm{C}, 60^{\circ} \mathrm{C}, 70^{\circ} \mathrm{C}$ separately the reactions were carried out many times with headspace equilibrium times and time intervals at $1 \mathrm{~min}, 10 \mathrm{~min}$ respectively. After each extraction, the block was removed from the headspace bottle and put it into a desktop oscillator (opening state, making the wood block have contact with outside air so that the camphor kept releasing) at the same temperature as that in the HS-GC to balance for a few hours. Then the headspace was extracted multiple times and detected using gas chromatography, and repeated several times until the release rate of camphor in the wood block was balanced (Díaz Maroto et al. 2004). Each time buffing only occurred in the first extraction. Wood blocks were only used at the same temperature, and when the temperature changed the block was replaced. Each time was noted to correct the standard curve.

\section{Static headspace gas chromatography (HS-GC) conditions}

Headspace sampling is employed with gas chromatography $(\mathrm{GC})$ in numerous fields and with a variety of applications (Suhua et al. 2018). Head-space sampler conditions were an equilibrium temperature of $40^{\circ} \mathrm{C}, 50^{\circ} \mathrm{C}, 60^{\circ} \mathrm{C}, 70^{\circ} \mathrm{C}$. Carrier gas pressure was $0.15 \mathrm{MPa}$, and pressurized pressure was $0.2 \mathrm{MPa}$. Extractions were repeated 10 times with $10 \mathrm{~min}$ time intervals. The vibration conditions were strong concussion, and the pressing time of the sample vial was $10 \mathrm{~s}$. The filling time of the quantitative ring was $15 \mathrm{~s}$, and the time of transfer to GC was $20 \mathrm{~s}$.

$\mathrm{GC}$ test conditions was FID detector at $250^{\circ} \mathrm{C}$, and injection port temperature was $220^{\circ} \mathrm{C}$ with a pressure of $0.14 \mathrm{MPa}$. Injection port split ratio was 2:1. GC column box using temperature programmed mode for $60^{\circ} \mathrm{C}$ and kept running for $6 \mathrm{~min}$, programmed to rise from $120^{\circ} \mathrm{C}$ to $150^{\circ} \mathrm{C}$, isothermal for $1.5 \mathrm{~min}$, then reduced at $120^{\circ} \mathrm{C}$ to $60^{\circ} \mathrm{C}$ and isothermal for $0.5 \mathrm{~min}$, with a total operation of $9.5 \mathrm{~min} . \mathrm{H}_{2}$ flow rate was $30 \mathrm{~mL} \cdot \mathrm{min}^{-1}$. Air flow rate was $400 \mathrm{~mL} \cdot \mathrm{min}^{-1}$ and tail flow rate was $25 \mathrm{~mL} \cdot \mathrm{min}^{-1}$. 


\section{Analysis of oxygen content}

Using the detected changes of oxygen content to correct the multiple extraction signals. Take an empty headspace bottle to gland, using headspace extract multiple times to measure the change of oxygen signal value. Head-space equilibrium temperature was $70^{\circ} \mathrm{C}$ and equilibrium time was $1 \mathrm{~min}$. Time interval was $5 \mathrm{~min}$ with 10 extractions. Carrier gas pressure was $0.055 \mathrm{MPa}$. GC test conditions was TCD detector $220^{\circ} \mathrm{C}$, injection port temperature $200^{\circ} \mathrm{C}$, pressure $0.05 \mathrm{MPa}$, injection port split ratio $0.1: 1$. GC column box using temperature $60^{\circ} \mathrm{C}$ for $4 \mathrm{~min}$, the exit gas velocity was $3 \mathrm{~mL} \cdot \mathrm{min}^{-1}$.

\section{RESULTS AND DISCUSSION}

\section{Release of camphor from C. camphora wood}

Headspace gas chromatography (HS-GC) is a powerful technique for the analysis of volatile compounds released from plants (Colina-Coca et al. 2013, Wani et al. 2011). The release amount of the camphor at single time was detected by HS-GC. Then, the corresponding release rate and cumulative release content were calculated from this detection. Compared with camphor, the early experiment found that the content of $\alpha$-terpineol (Sousa et al. 2008), linalool, eucalyptol, etc. were very low, and are close to zero when detection time was over $10 \mathrm{~h}$. Therefore, the release of camphor from C. camphora wood was the focus of this study (Singh et al. 2008).

From Fig. 1, the detection content measured by HS-GC decreased with the increasing of detection times at different heating conditions. It was due to the high content of camphor and little obstacles of camphor' release channels in new section longitudinal and transverse in short time. After a period of time, the contents of camphor in the surface significantly decreased, while channels of resistance increased such as vessel, perforate, ultrafine pore on pit membrane and etc, because they were far away from the surface regional (Varlet et al. 2013). The release of camphor tended to decrease to stabilization per unit time. In the same detection time, higher heating temperatures led to the higher detection of camphor content. The Brownian motion of camphor molecules get faster when temperatures get higher, thus the rate of camphor accelerated the overflow from C. camphora wood. On the one hand, the higher heating temperature led to the greater expansion of ultrafine pores on pit membrane of the cell wall. However, the lower resistance camphor overflow, the higher detection content of camphor per unit time (Gozlekci et al. 2011). Thus, with increased detection times, the amplitude of camphor detection increased.

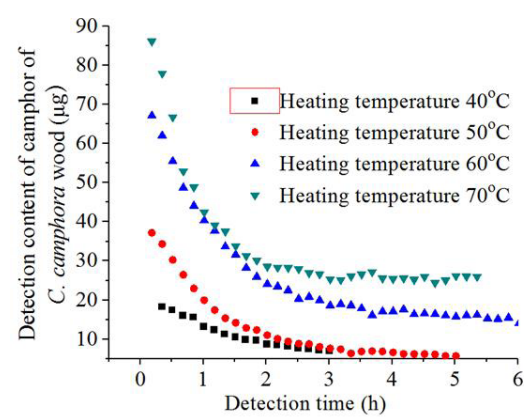

Fig. 1: The content of camphor from C. camphora wood under different detection temperatures and times.

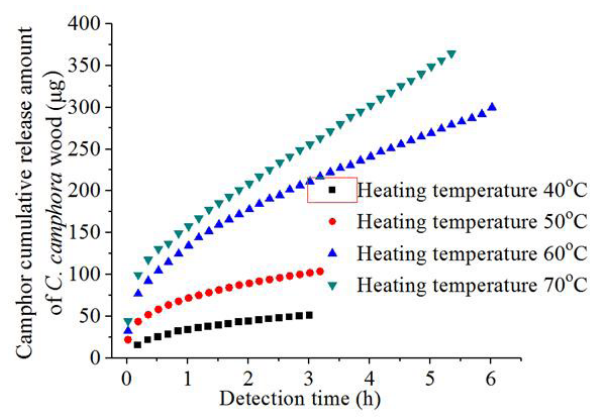

Fig. 2: The camphor cumulative release amount of C. camphora wood in different temperature. 
It could be seen from Fig. 2, that the cumulative camphor release at $40^{\circ} \mathrm{C}$ and $50^{\circ} \mathrm{C}$ was significantly less than at higher temperatures, such as $60^{\circ} \mathrm{C}$ and $70^{\circ} \mathrm{C}$. As detection time increased, increases in the cumulative release amount of camphor was not obvious. The cumulative release of camphor significantly increased at $60^{\circ} \mathrm{C}$ and $70^{\circ} \mathrm{C}$ conditions.

A significant positive correlation was found between the camphor release rate and heating temperature in the same range of detection time (Fig. 3). In other words the higher the heating temperature, the faster the release rate of camphor. The release rate of camphor was obviously higher at temperatures of $60^{\circ} \mathrm{C}$ and $70^{\circ} \mathrm{C}$ than those at $40^{\circ} \mathrm{C}$ and $50^{\circ} \mathrm{C}$ in the same detection time. The release rate of camphor rapidly decreased with increases in heating time of $0 \sim 2.5 \mathrm{~h}$, although the release of camphor stabilized when the detection time was over $2.5 \mathrm{~h}$.

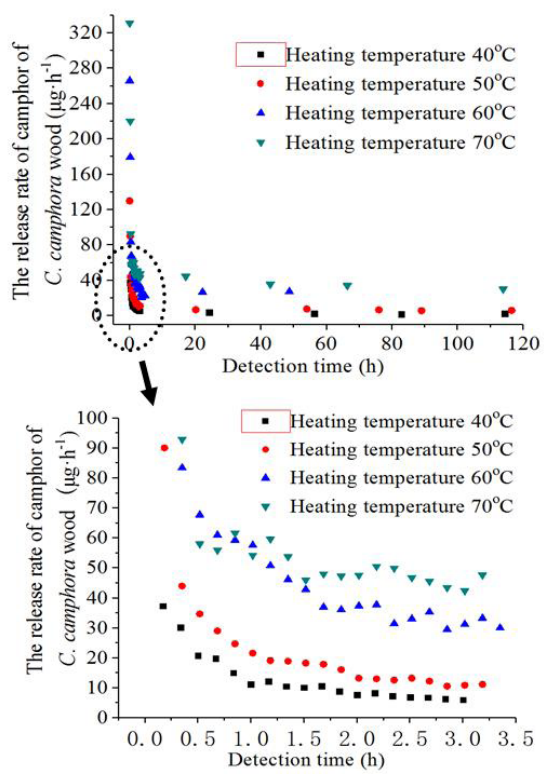

Fig. 3: The release rate of camphor of C. camphora wood at different temperatures.

With increased temperature, the camphor release rate increased due to increases in Brownian motion and pits on the wood cell wall and vessel (He et al. 2007). At higher temperatures, the faster speed of Brownian motion of camphor and the overflow rate of camphor accelerated from C. camphora wood. The higher heating temperature, the greater expansion of ultrafine pores on cell wall pit membrane. The less resistance to camphor overflow led to faster release rates. In addition, this release behavior may also be due to overcoming the inter molecular forces of camphor being released from the C. camphora wood, an endothermic process (Kaygin et al. 2009). Thus with increased heating temperatures, the rate of camphor release also accelerated gradually.

The total release amount of camphor was higher at temperatures of $60^{\circ} \mathrm{C}$ and $70^{\circ} \mathrm{C}$ than at $40^{\circ} \mathrm{C}$ and $50^{\circ} \mathrm{C}$ (Fig. 4). However, with increased heating time, the growth of total release amounts of camphor gradually slowed. When C. camphora wood placed in a bottle in the HS-GC, the camphor concentration is different than the $C$. camphora wood surface in the environment (Paolini et al. 2005), which increased the release rate. With increases in the detection time, the camphor on the surface of C. camphora wood gradually evaporated leading to the inner camphor 
spreading to the outer surface gradually. Thus, the mass transfer driving force became smaller and the release rate decreased.

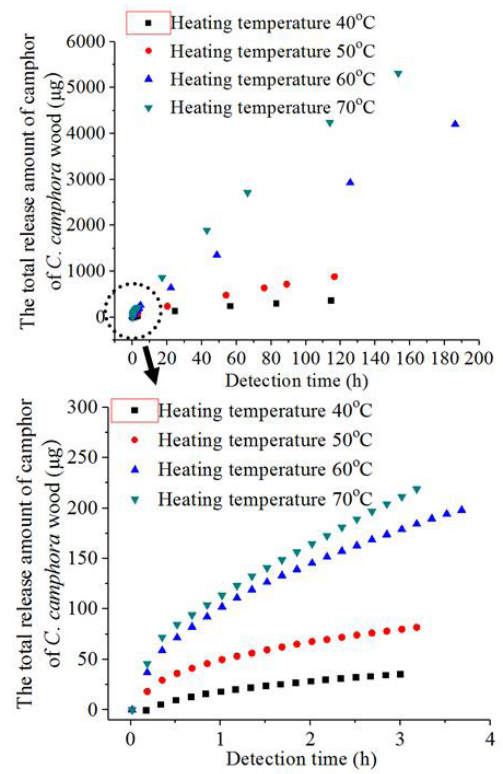

Fig. 4: The total amount of camphor released at different temperatures.

\section{The relationship between camphor release content and detection time}

The linear fit between camphor content in detection content and time shows that the content of camphor release at $0 \sim 1.4 \mathrm{~h}$ was approximately linear (Fig. 5) (Gawde et al. 2014). The linear relationship was clear at test times of $40^{\circ} \mathrm{C}, 50^{\circ} \mathrm{C}$ and $60^{\circ} \mathrm{C}$, and slightly worse at $70^{\circ} \mathrm{C}$, although variation was not significant at different temperatures.

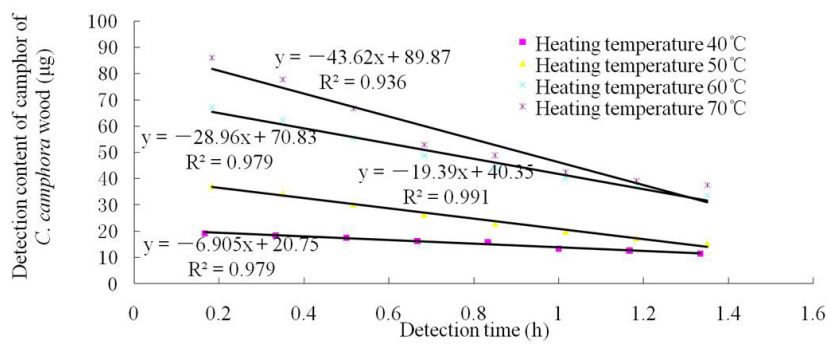

Fig. 5: The detection of camphor at 0 1.4 by by $H S-G C$.

\section{Development of the empirical model for predicting camphor release content}

A linear regression $(y=a+b t)$ was used to fit the camphor content $y(\mu g)$ and detection time $t(\mathrm{~d})$, with " $a$ ", " $b$ " representing correlation coefficients (Tab. 1). The correlation coefficient (r) reached a significant level, which indicates that under the experimental conditions, camphor release belongs to a zero-level kinetic equation reaction $(d y / d t=b)$ (Alcarde et al. 2010), where " $a$ " 
represents the initial release amount of camphor and " $b$ " represents the release rate of camphor. The linear regression equation of camphor content " $y$ " and time " $t$ " changes with the increases in temperature, indicating that the " $a$ " and " $b$ " values are to temperature.

Tab. 1: The regression coefficient between camphor content and time.

\begin{tabular}{|c|c|c|c|}
\hline \multirow{2}{*}{ Temperature $\left({ }^{\circ} \mathbf{C}\right)$} & \multicolumn{3}{|c|}{ Regression equation } \\
\cline { 2 - 4 } & $\mathbf{a}$ & $\mathbf{b}$ & $\mathbf{r}$ \\
\hline 40 & 20.753 & -6.9052 & 0.9797 \\
\hline 50 & 40.35 & -19.392 & 0.9915 \\
\hline 60 & 70.834 & -28.965 & 0.9798 \\
\hline 70 & 89.878 & -43.621 & 0.9369 \\
\hline
\end{tabular}

According to the analysis, values of " $a$ " and " $t$ " were linearly correlated with temperature. Tab. 2, the coefficient $\beta$ of T is the effect on strength of temperature on the value of " $a$ ", called the initial release amount temperature coefficient of camphor. The $\eta$ is the effect of strength and temperature on the value of " $a$ ", the release rate temperature coefficient of camphor. The greater value of $\beta$ and $\eta$ indicates a larger effect of temperature on the value of " $a$ " and " $b$ ", conversely was smaller.

The regression equation between the detection content of camphor y $(\mu \mathrm{g})$ temperature $\mathrm{T}\left({ }^{\circ} \mathrm{C}\right)$ and time $\mathrm{t}(\mathrm{h})$ is $\mathrm{y}=-75.369+2.3786 . \mathrm{T}+(41.125-1.1972 . \mathrm{T})$ in the heating temperature range of $40 \sim 70^{\circ} \mathrm{C}$ and detection times ranging from $0 \sim 1.4 \mathrm{~h}$.

Tab. 2: The regression equation $(a=\alpha+\beta T, b=\rho+\eta T)$ between the value " $a$ " and " $b$ " and temperature $\left({ }^{\circ} \mathrm{C}\right)$.

\begin{tabular}{|c|c|c|c|}
\hline \multicolumn{4}{|c|}{ Regression equation } \\
\hline Value a & $\mathbf{r}$ & Value b & $\mathbf{r}$ \\
\hline$-75.369+2.3786 \mathrm{~T}$ & 0.9939 & $41.125-1.1972 \mathrm{~T}$ & 0.9912 \\
\hline
\end{tabular}

It can be seen from the above analysis that the amount $y$ of detected camphor and values of "a" and "b" in a time linear equation with time and temperature were negatively correlated and positive correlation, respectively. It can be confirmed that suitability of the fitted equation, can confirm the coupling effect of camphor content in the release process with temperature and time detection with HS-GC (Wang et al. 2019, Caron et al. 2013).

\section{CONCLUSIONS}

The release mechanism of volatile substances in C. camphora wood and the analysis of the camphor volatilization process in C. camphora wood was analyzed using HS-GC technology. This research indicates a potential effect on indoor air quality and human health.

The detection content of camphor under four heating temperatures decreased with the increases in detection time. The higher the temperature, the higher detection content of camphor by HS-GC at the same time periods. The cumulative release amount of camphor was relatively slow at $40^{\circ} \mathrm{C}$ and $50^{\circ} \mathrm{C}$, and the cumulative release amount of camphor increased rapidly at the heating temperature of $60^{\circ} \mathrm{C}$ and $70^{\circ} \mathrm{C}$. The release rate of camphor from C. camphora wood and heating temperature were positively correlated. The higher of the heating temperature, the 
greater the release rate of camphor. The releasing camphor mathematical model was established. This analysis has coupled the relationship between the detection content of camphor y $(\mu \mathrm{g})$ and temperature $\mathrm{T}\left({ }^{\circ} \mathrm{C}\right)$ and time $\mathrm{t}(\mathrm{h})$, in the heating range of $40 \sim 70^{\circ} \mathrm{C}$ and detection time range of $0 \sim 1.4 \mathrm{~h}$. This study has great significance for the comprehensive understanding of the release mechanism of camphor from C. camphora wood and has applications in the research and development of aromatherapy, medical, chemical industries.

\section{ACKNOWLEDGMENTS}

This research was supported by the Natural Science Foundation of China (No. 31760191), Natural Science Research Project [2017]011 of Education Department of Guizhou Province, P. R. China and Projects of Science and Technology Plan of Fujian Province (2018S0038).

\section{REFERENCES}

1. Alcarde, A.R., Souza, P.A.D., Belluco, A.E.D.S., 2010: Volatilization kinetics of secondary compounds from sugarcane spirits during double distillation in rectifying still. Scientia Agricola 67(3): 280-286.

2. Alves, G.L., Franco, M.R., 2003: Headspace gas chromatography-mass spectrometry of volatile compounds in Murici (Byrsonima crassifolia L. Rich). Journal of Chromatography A 985(1-2): 297-301.

3. Liu, M.L., Li C.F., Liu, Y.L., 2019: Physical and mechanical properties of modified poplar wood by heat treatment and impregnation of sodium silicate solution. Wood Research 64(1): 145-154.

4. Buchbauer, G., Wallner, I.M., 2016: Essential oils: properties, composition and health effects. Encyclopedia of Food \& Health 2: 558-562.

5. Calejo, I., Moreira, N., Araújo, A.M., Carvalho, M., Bastos, M.D.L., Pinho, P.G.D., 2016: Optimisation and validation of a HS-SPME-GC-IT/MS method for analysis of carbonyl volatile compounds as biomarkers in human urine: Application in a pilot study to discriminate individuals with smoking habits. Talanta 148: 486-493.

6. Caron, L., Deslauriers, A., Mshvildadze, V., Pichette, A., 2013: Volatile compounds in the foliage of balsam fir analyzed by static headspace gas chromatography (HS-GC): An example of the spruce budworm defoliation effect in the boreal forest of Quebec, Canada. Microchemical Journal 110: 587-590.

7. Colina-Coca, C., González-Peña, D., Vega, E., Ancos, B.D., Sánchez-Moreno, C., 2013: Novel approach for the determination of volatile compounds in processed onion by headspace gas chromatography-mass spectrometry (HS GC-MS). Talanta 103: 137-148.

8. Cox, S.S., Little, J.C., Hodgson, A.T., 2002: Predicting the emission rate of volatile organic compounds from vinyl flooring. Environmental Science \& Technology 36(4): 709-714.

9. Díaz-Maroto, M.C., Eva Sánchezpalomo, A., Pérezcoello, M.S., 2004: Fast screening method for volatile compounds of oak wood used for aging wines by headspace SPME-GCMS (SIM). Journal of Agricultural \& Food Chemistry 52(23): 6857-61.

10. Dubrova, M.A., Mindlin, L.O., Shchedrina, M.M., Belfer, A.G., Nikitina, M.A., Rudenko, B.A., 1990: Headspace gas chromatography with open-tubular columns for determining the evaporation rate of essential oils, perfumery compositions and perfumes. Journal of Chromatography A 520(1): 169-174. 
11. Gawde, A., Cantrell, C.L., Zheljazkov, V.D., Astatkie, T., Schlegel, V., 2014: Steam distillation extraction kinetics regression models to predict essential oil yield, composition, and bioactivity of chamomile oil. Industrial Crops \& Products 58: 61-67.

12. Gozlekci, S., Kafkas, E., ErciSli, S., 2011: Volatile compounds determined by HS/GC-MS technique in peel and pulp of fig (Ficus carica L.) cultivars grown in Mediterranean region of Turkey. Notulae Botanicae Horti Agrobotanici Cluj-Napoca 39(2): 105-108.

13. He H.S., Pan Z.H., Liang Y.B., Luo Bei, Qiu Jian, 2019: Anatomy comparative study of Aquilaria sinensis in different agar wood induced methods. Journal of Forestry Engineering 4(5): 54-59.

14. Hsiumei, C., Huahsien, C., Lai, Y.M., Chen, C.Y., Hunglung, C., 2010: Carbonyl species characteristics during the evaporation of essential oils. Atmospheric Environment 44(18): 2240-2247.

15. Hyun, H.B., Boo, K.H., Kang, H.R., Cho, S.K., 2015: Analysis of mint essential oils from Jeju Island, Korea by gas chromatography-mass spectrometry and headspace-gas chromatography-mass spectrometry. Journal of Applied Biological Chemistry 58(2): 175-181.

16. Ibrahim, M., Kainulainen, P., Aflatuni, A., Tiilikkala, K., Holopainen, J.K., 2008: Insecticidal, repellent, antimicrobial activity and phytotoxicity of essential oils: With special reference to limonene and its suitability for control of insect pests: Review. Agricultural \& Food Science in Finland 10(3): 243-259.

17. Jensen, L.K., Larsen, A., Mølhave, L., Hansen, M.K., Knudsen, B., 2001: Health evaluation of volatile organic compound (VOC) emissions from wood and wood-based materials. Archives of Environmental Health An International Journal 56(5): 419-432.

18. Johann, S., Cisalpino, P.S., Watanabe, G.A., Cota, B.B., Siqueira, E.P.D., Pizzolatti, M.G., Zani, C.L., Resende, M.A.D., 2010: Antifungal activity of extracts of some plants used in Brazilian traditional medicine against the pathogenic fungus Paracoccidioides brasiliensis. Pharmaceutical Biology 48(4): 388-396.

19. Korukluoglu, M., Gurbuz, O., Sahan, Y., Yigit, A., Kacar, O., Rouseff, R., 2009: Chemical characterization and antifungal activity of Origanum onites L. essential oils and extracts. Journal of Food Safety 29(1): 144-161.

20. Kusumoto, N., Shibutani, S., 2015: Evaporation of volatiles from essential oils of Japanese conifers enhances antifungal activity. Journal of Essential Oil Research 27(5): 380-394.

21. Li, Y., Qi, Y., 2019: Study on the dyeing properties of Cinnamomum camphora fruit dyes on wood veneer. Journal of Forestry Engineering 4(4): 1-7.

22. Lisec, J., Schauer, N., Kopka, J., Willmitzer, L., Fernie, A.R., 2006: Gas chromatography mass spectrometry-based metabolite profiling in plants. Nature Protocol 1(1): 387-96.

23. Kaygin, B., Gunduz, G., Aydemir, D., 2009: The effect of mass loss on mechanic properties of heat-treated paulownia wood. Wood Research 54(2): 101-108.

24. Menéndez, J.C.F., Sánchez, M.L.F., MartıNez, E.F., Ur1A, J.E.S., Sanz-Medel, A., 2004: Static headspace versus head space solid-phase microextraction (HS-SPME) for the determination of volatile organochlorine compounds in landfill leachates by gas chromatography. Talanta 63(4): 809-814.

25. Miyazawa, M., Hashimoto, Y., Taniguchi, Y., Kubota, K., 2001: Headspace constituents of the tree remain of Cinnamomum camphora. Natural Product Letters 15(1): 63-69.

26. Olabode, O.O., Arueya, G.L., 2016: Analysis and identification of the volatile compounds in melon-bitter leaf soup. African Journal of Food Science 10(11): 302-312. 
27. Paolini, J., Costa, J., Bernardini, A.F., 2005: Analysis of the essential oil from aerial parts of Eupatorium cannabinum subsp. corsicum (L.) by gas chromatography with electron impact and chemical ionization mass spectrometry. Journal of Chromatography A 1076(1-2): 170-182.

28. Roszaini, K., Nor Azah, M.A., Mailina, J., Zaini, S., Mohammad, F.Z., 2013: Toxicity and antitermite activity of the essential oils from Cinnamomum camphora, Cymbopogon nardus, Melaleuca cajuputi and Dipterocarpus sp. against Coptotermes curvignathus. Wood Science and Technology 47(6): 1273-1284.

29. Lizarraga E., Angel Irigoyen, Belsue V., Elena González-Peñas, 2004: Determination of chloroanisole compounds in red wine by headspace solid-phase microextraction and gas chromatography- mass spectrometry. Journal of Chromatography A 1052(1-2): 145-149.

30. Shen J., Jiang L.Q. 2018: A review of research on VOCs release from wood-based panels. Journal of Forestry Engineering 3(6): 1-10.

31. Singh, P., Srivastava, B., Kumar, A., Dubey, N.K., 2008: Fungal contamination of raw materials of some herbal drugs and recommendation of Cinnamomum camphora oil as herbal fungitoxicant. Microbial Ecology 56(3): 555-560.

32. Sousa, D.P.D., Jr, L.Q., Almeida, R.N.D., 2008. Evolution of the anticonvulsant activity of $\alpha$-terpineol. Pharmaceutical Biology 45(1): 69-70.

33. Staszek, D., Orłowska, M., Rzepa, J., Wróbel, M. S., Kowalska, T., Szymczak, G., 2014: Fingerprinting of the volatile fraction from selected thyme species by means of headspace gas chromatography with mass spectrometric detection. Journal of AOAC International 97(5): 1250-1261.

34. Suhua, Y., Shunzhong, L. U., Mi, Q. , Yufen, L., 2018: Analysis on components of high content o-cymene from Cinnamomum camphora essential oil. Journal of Forestry Engineering 3(1): 49-53.

35. Ubeda, C., Callejon, R.M., Hidalgo, C., Torija, M.J., Mas, A., Troncoso, A.M., Morales, M.L., 2011. Determination of major volatile compounds during the production of fruit vinegars by static headspace gas chromatography-mass spectrometry method. Food Research International 44(1): 259-268.

36. Varlet, V., Smith, F., Augsburger, M., 2013: Validation of methane measurement using headspace-GC-MS and quantification by a stable isotope-labeled internal standard generated in situ. Journal of Separation Science 36(12): 1967-1972.

37. Wang, C., Li, M., Zhang, L., Fu, S., 2016: Extraction of natural dyes from Cinnamomum camphora (L.) presl fruit and their application on wool fabric. Textile Research Journal. 87(20): 2550-2560.

38. Wang, C.Y., Yang, Z.L, Wang, X., Yu ,Q.Q. 2019: New research progress of functional wood. Journal of Forestry Engineering 4(3): 10-18.

39. Wani, B.A., Ramamoorthy, D., Rather, M.A., Ganai, B.A., Masood, A., Zargar, M.A., Wani, I., 2011. Headspace solid-phase microextraction (HS-SPME) gas chromatography mass spectrometric (GC-MS) analysis of the volatile aroma components of Gentiana kurroo Royle. Journal of Pharmacy Research 4(9): 2943-2945.

40. Zhong, L., Wang, Y., Peng, W., Liu, Y., Wan, J., Yang, S., Li, L., Wu, C., Zhou, X., 2015: Headspace solid-phase microextraction coupled with gas chromatography-mass spectrometric analysis of volatile components of raw and stir-fried fruit of C. pinnatifida (FCP). Tropical Journal of Pharmaceutical Research 14(5): 891-898. 
QUAN Li

${ }^{1}$ Fujian Agriculture and Forestry University

College of Material Engineering

FuzHou

China

${ }^{2}$ Kaili University

KAILI

China

Huimin Z Hang

Guizhou University

College of Forestry

GuiYang

China

Hongguang Yan

Kaili University

KAILI

China

Wenyu Qi, Jinguo Lin*, Jieing Li*

Fujian Agriculture and Forestry University

College of Material Engineering

FuzHOU

CHINA

*Corresponding authors: fjlinjg@126.com and nfuljq@163.com 
